\title{
Justicia comunitaria o de las razones para disentir ${ }^{1}$
}

\author{
Community Justice or Reasons for Dissenting
}

THAISA DE SOUZA

Universidad del Rosario, Colombia

RECEPCIÓN 22/I 2/20I4 • ACEPTACIÓN: I6/O6/20I 5

RESUMEN El presente ensayo reflexiona en torno al problema de la justicia comunitaria como posibilidad para desenredar las ambiguas lógicas tutelares de pacificación y sometimiento. Esto invita a repensar los fines y confines de lo que revela la tradición política moderna. Para ello, comienzo analizando dos categorías clave: pacificación y confinamiento, las cuales constituyen lo que se podría llamar paradoja erosionadora de los derechos. Posteriormente, se aborda el tiempo y su papel de formador del entendimiento y de la interpretación de las injusticias cometidas, incluyendo al individuo y su padecimiento. Luego, busco postular la asunción de dos vertientes progenitoras de los modos de enlazar la justicia a los distintos contextos de sentido: el lenguaje del conflicto y la interpelación moral de los sujetos; proyectando así las necesarias acciones de articulación de los disensos. Finalizo exponiendo una idea de proyecto ético-político de materialización de

I. La escritura de este artículo se deriva de un esfuerzo de reflexión planteado alrededor de la justicia comunitaria y ciertos problemas contemporáneos del derecho como forma de esbozar unas claves conceptuales para la comprensión del proceso reconstitutivo de la justicia y sus regímenes discursivos. Agradezco enormemente la interlocución labrada con Ricardo Salas, docente de la Universidad Católica de Temuco, quien, con su cálida y aguda percepción, enfatizó aspectos teóricos definitivos para la depuración de algunos argumentos. 
justicias comunitarias, que reposara sobre la triple agencia pedagógica de la afirmación del lenguaje, la invocación colectiva de acontecimientos para articular las memorias y la legitimación cohesionadora de saberes. El objetivo es demostrar que el derecho gobernante, sea cual sea su lenguaje, parece redundar en una máquina práctica y pensamiento ajustado a las contingencias normativas de creación de hegemonías y categorías discursivas, ante lo cual es necesario generar propuestas contra-hegemónicas del derecho, como es la llamada justicia comunitaria.

PALABRAS CLAVE Justicia, comunidad, lenguaje, sujeto.

ABSTRACT The present essay reflects on the problem of community justice as a means of unravelling the ambiguous guiding logics of pacification or subjection. This invites us to re-think the objects and boundaries of what the modern political tradition shows us. I will start by analysing two key categories, pacification and confinement, which constitute what might be called the paradox which erodes rights. We will then look at time and its role in forming understanding and interpretation of the injustices committed, including those against the individual and his condition. Then I search to apply the assumption of two parent strands of the ways of linking justice to the different contexts of meaning: the language of conflict and moral questioning of subjects; thus projecting the necessary actions to articulate dissent. I will finish by expounding an idea for a ethical-political project to create a system of community justice, based on the triple didactic agency of strengthening language, collective invocation of events to coordinate memories, and the legitimisation of different types of knowledge to create cohesiveness. My object is to show that the law, in whatever language it is expressed, always seems to result in a practical machine and a way of thinking suited to the legal mechanisms for the creation of hegemonies and discursive categories, and that in the face of this result it is necessary to generate counter-hegemonic proposals for the legal system, such as that known as community justice.

KEYWORDS Justice, community, language, subject.

\section{Pacificación y confinamiento como núcleos contenedores}

Es quizás incomodo arrancar un discurso sobre la justicia evidenciando de antemano los artilugios que encabezan hoy en día las portentosas o sutiles es- 
trategias de encuadramiento y modelación de las conductas. Marginación del conflicto, puesta en suspenso de las desigualdades e imperatividad de la ley y sus correlatos racionales de formación del consenso son el menú de opciones con el que la hegemonía de las lógicas estatales desenraizan el pueblo y la vida del pueblo de los surcos de la política y de la cultura.

Desglosemos esas operaciones. Lo que hoy se evidencian como ideologías tecnocráticas presentes en la elaboración discursiva del derecho apuntan claramente en un primer momento al conjunto de acciones jurídicas y normativas que hemos venido denominando de pacificación. Alzada sobre el modelo de homologación y valorización de los derechos y anclada en la creencia de sus tareas programáticas y distributivas, dicha inversión estatal se expresa en un plan más visible y estructural de la funcionalidad gubernamental. La contención y el acomodamiento de los conflictos revisten con un velo benevolente y protector este abarcador comodín terapéutico de la actualidad. A su vez, el mote del confinamiento, derivado de las políticas de mejoría del acceso a la justicia y derechos materiales, se deriva en el modelo de desreglamentación y flexibilización legal, conducido a través de la compensación moral a los sujetos por la vía del reconocimiento de sus capacidades y singularidades, y que se traduce en herramienta para facilitar procesualmente y mitigar el costo del acceso a los derechos. Convergiendo adicionalmente hacia la sintomática reclusión, en nichos especializados o relegados, de la conflictividad.

En coalición, pacificación y confinamiento constituirían lo que se podría llamar la paradoja erosionadora de los derechos. Por un lado, la ilusión depositada en la promesa garantista y de bienestar suministrada en políticas de aseguramiento de la igualdad; por otro, la precarización y pulverización de los sistemas jurídicos tradicionales en búsqueda de la consecución de políticas comprometidas con el recientemente consagrado respeto por las diferencias (cf. Soler, 20I I: cap. 5). Si bien éstas han sido, desde los actuales sistemas constitucionales, la fuente de revigorados proyectos jurídicos de efectividad de muchas prácticas identitarias, mantenemos nuestras grandes reservas sobre la cuestión, en tanto las diferencias se perfilan desde los nuevos tiempos como el repertorio insoslayable de significación para el sujeto, sin el cual la misma individualidad no se justificaría. Eso que para los términos de Colette Soler se configura a partir de tres modos convergentes de asunción del enderezamiento democrático actual: la esquizofrenización del superyó consumidor, fijado en un goce que prescinde de cualquier mediación con sus semejantes; la pulverización de los semblantes, patente en la medida en que se multiplican los ros- 
tros de la diferencia y se fragmentan los vínculos entre ellos; y las formas de la concertación democrática que pretenden el consenso en razón de su mismo autismo excluyente (cf. Soler, 20 I I: 835-840), pues como condensa Soler, «en detrimento de toda disparidad, se trata de uno mismo hablándose a sí mismo» (Soler, 20I I: 838-839).

Lo que esos procesos canalizan como resultante práctica y el fraude discursivo que se instaura corroen la misma performance (des)constructiva de la justicia (cf. Derrida, 20 I0: $5 \mathrm{I}^{-5} 8$ ), la cual pone de relieve su carácter de interrupción de la normalidad del derecho, marcando su inequívoca expresión de apelo y de acogida infinita del otro; llevándonos al concepto de justicia que Jacques Derrida resalta del pensamiento de Levinas, confirmando que la «equidad, aquí, no es la igualdad, la proporcionalidad calculada, la distribución equitativa o la justicia distributiva, pero la disimetría absoluta» (Derrida, 20I0: 42). De ahí que se podría, de modo a asumir concretamente los procedimientos mencionados, identificar la pacificación al dispositivo político de contención de los conflictos; el confinamiento al dispositivo jurídico de ampliación del acceso y, además, agregar la categoría reguladora del consenso como un dispositivo racional de conformación del diálogo, ubicándolo así como el recurso modelador que ensalza los dos sistemas anteriormente descritos.

Si trasladamos esas lógicas al problema que nos interesa en este momento, los fenómenos de la justicia comunitaria, y nos atenemos a lo que hemos comprobado en el trabajo de campo realizado entre diversas experiencias de Brasil, terminaríamos sin mucha demora percibiendo que los principios supuestos en una vía comunitaria de manejo de los conflictos —o sea, la discursividad erigida sobre referentes propios, la vinculación consciente a los procesos de la dinámica comunitaria y la capacidad de invertir recursos individuales y colectivos para la transformación activa de la necesidades- se dejan fácilmente permear por los fines y razonamientos de los dispositivos contenedores del conflicto social.

La investigación realizada entre los años 20IO-20I2 se acercó de forma bastante inquisitiva a experiencias de comunitarización de la justicia en cuatro estados brasileros, abordando casos diversos de poblaciones urbanas periféricas y precarizadas por su condición de pobreza y dificultoso acceso a distintos derechos. Estos ejemplos operativos se caracterizan por una institucionalidad híbrida, advenida del esfuerzo local de suplir carencias puntuales y, al tiempo, amparada, en mayor o menor medida, por aparatos de orden público o social. En lo general, atienden a la procedimentalización expedita de demandas e in- 
tereses pero no conducen a formas autónomas y emancipadas de tratamiento de los desacuerdos e insatisfacciones vividos. Se conforman de esquemas preconfigurados de mediaciones de conflictos de posiciones contrarias que se tramitan a través de la exposición de hechos y la concertación hablada. Según predican los manuales y las enseñanzas socializadas en Brasil, la mediación debe ser apenas facilitada por un tercero, siendo las partes involucradas las responsables por el deslinde del caso y promotoras activas de la transformación de los aspectos problematizantes. Aún así, en lo que pudimos averiguar en el terreno cotidiano de manejo de los conflictos, termina siendo el mediador, como agente socialmente reconocido y autorizado, quien, con sus limitados recursos argumentativos, actua directamente para resolver la cuestión. ${ }^{2}$

No sin razón la justicia comunitaria aquí propugnada y más adelante expuesta, propone la construcción paradigmática de esa línea de fuga que se establece como desvío creativo y disruptivo ante los avances reformadores de lo ya establecido estructuralmente. Es por ese deseo de no sometimiento que cobra significado el planteamiento de las mediaciones discursivas de los derechos adscritos en los anhelos transformadores de la justicia comunitaria. A partir de la reconducción de los vínculos sociales y de la exhumación abierta

2. Dicha investigación fue coordinada por el profesor Antonio Carlos Wolkmer, de la Facultad de Derecho de la Universidad Federal de Santa Catarina (Florianópolis, Brasil), y estuvo financiada por el Consejo Nacional de Desarrollo Científico y Tecnológico (CNPq). Las experiencias visitadas fueron: el Programa Justicia Comunitaria de las ciudades-satélites de Ceilândia, Taguatinga y Samambaia (Distrito Federal); el Mostrador (Balcão) de Derechos de la ciudad de Río de Janeiro (Río de Janeiro); las Centrales de Conciliación, Mediación y Arbitraje de las ciudades de Recife y Olinda (Pernambuco); y los varios Núcleos de Mediación Comunitaria de las ciudades de Fortaleza, Caucaia e Russas (Ceará). Se puede ver, al respecto, dentro del informe final presentado al CNPq el texto: "Justiça comunitária: aproximações sobre una causa movediça». Es importante resaltar que esos mecanismos alternativos de administración de la justicia instituidos en Brasil son representativos de una transfiguración muy acotada de la justicia que se produce, con variados matices, en otras partes de América Latina. Podemos traer a colación el ejemplo de Colombia, otro escenario donde prácticas socioculturales del derecho, como son los jueces de paz, los conciliadores en equidad, la justicia ancestral de comunidades negras y la misma jurisdicción indígena, previstas por la Constitución Política de I99I, no han podido plasmarse muy fácilmente como manifestaciones contrahegemónicas de justicia, en el seno de un Estado abanderado como multicultural y plural. 
de las miríadas de formas de lo popular, en cuanto reivindicación aún inacabada de diseños culturales que buscan circular y expandirse por la sociedad (cf. Martín-Barbero, 20IO: I-4I), ${ }^{3}$ vamos llegando a los designios propios de la justicia comunitaria: la apropiación de nuestros conflictos y la elaboración de nuestros horizontes normativos. Para así seguir en vigilia constante respecto del andamiaje de los vínculos sociales, de par en par, fragmentados y recortados por las necesidades de composición hegemónica del capital, el encargado de dictaminar el lugar de los sujetos, ahora asentado sobre la posición de persona cosificada que, a duras penas, puede, cuando mucho, saltar sobre los muros que coartan su acción política y moral (cf. Soler, 20I I: cap. 5).

Surge entonces la pregunta cabal. ¿Qué procesos y dinámicas hay existentes para envolver y densificar los conflictos por medio de una semántica propia, asumida desde la disputa por un dispositivo sociocultural legítimo y válido, entendido como el modo en que se consigna la aceptación y apreciación social de unas actividades teñidas de valor (cf. Honneth, 20I0: 9-44)? La propuesta de auscultar los posibles indicios que conformarían una gestión normativa de índole comunitaria, en donde creemos afirmarse valores renovados de la justicia y de la vida democrática, es un camino laborioso pero quizás bastante auspicioso en la asunción del disenso. Siendo éste la brújula que permite sondear y navegar en medio de las injusticias, orientando las acciones de respuesta perentoria a la exclusión y al daño (cf. Villoro, 2007: I 5-4I).

Vale aclarar también que al referirnos al término de la justicia comunitaria pretendemos englobar, en el plano conceptual, las múltiples prácticas existentes que buscan elaborar parámetros normativos y maneras de gestionar conflictos sobre una base contextual, o sea, local y situada, ajena, en alguna medida, a la operatividad de la justicia oficial de los estados en que están subsumidas. La elasticidad de la definición permite contener experiencias disimiles y diversas; sin embargo, tenemos la firme disposición de confluir las variadas expresiones presentes — desde las justicias propias indígenas subalternizadas, pasando por las formas tradicionales o ancestrales ya mimetizadas, hasta aquellas situaciones de organizaciones grupales insurgentes, o simplemente populares y marginales- hacia una concepción político-filosófica consistente. Este esfuerzo teorético se inscribe abiertamente en este propósito.

3. La obra magistral de Martín-Barbero posee interesantes referentes discursivos para la reflexión de la categoría de pueblo y de la conducción casi siempre distorsionada de lo popular en el proyecto sociocultural de la modernidad. 


\section{Tiempo, memoria y voz de las injusticias}

La justicia de la justicia comunitaria exige, para atender a la sustancialidad de un disenso performativo, que inaugura una nueva controversia o presenta una resistencia, considerar de manera fundamental la incidencia formadora y histórica del tiempo en el cual ha trascurrido el daño y la carencia sufridos por los individuos. Teniendo claro que es la dimensión temporal que permite formar la comprensión y el reconocimiento del sufrimiento; además es la que permite contemplar la identificación de los grupos oprimidos en el período de acontecimiento de los hechos que marcaron su historia.

La primera acepción, o sea, la que atribuye al tiempo el papel de formador del entendimiento y de la interpretación de las injusticias cometidas, se debe a la obra maestra del filósofo español Reyes Mate. Para el agudo pensador, el peso teórico de la significación de la experiencia de la injusticia encuentra su ancla moral determinante en la verdad inscrita en el lenguaje (cf. Mate, 20 I I: 3 I-78). Lenguaje que se esgrimiría en la capacidad de poner al descubierto el mundo, y que en su ausencia dejarían a los acontecimientos y a sus múltiples llamados sin expresión lingüística en la realidad, redundando con el devenir histórico en injusticias normalizadas. También el hombre evade a su trabajo de responder a los gritos y reclamos del mundo cuando interpone a la privación y padecimiento del otro una abstracción conceptual que no hace justicia a la singularidad del individuo, que a partir de ese momento pasa a no importar y a ser sometida por la teoría y sus cómplices políticos (cf. Mate 20I I, 3 I-78).

El otro campo que se abre a la incidencia temporal en la redimensionalización de la justicia está compaginado en ciertos autores contemporáneos que han visto de forma crítica y reflexiva las irrupciones de movimientos de grupos excluidos, en algún aspecto, del reparto de recursos y valoraciones simbólicas distribuidos en el funcionamiento de la sociedad (Young, 2000).

El tiempo es lo que permite incluir al individuo y su sometimiento, derivado de una falta o necesidad insatisfecha, y finalmente contemplar las bases perenes que moldean el mundo social, político y económico, que según Paul Valéry se asientan sobre la creencia; de donde la imborrable marca del poder de las jerarquías y de los mitos (cf. Valéry, 1996: 98-99). Es sobre ese piso de creencia o confianza que tendríamos que erguir el levante de la memoria, como lenguaje comunicador del disenso, contra la inmutable permanencia de las cosas.

La justicia comunitaria, si es capaz de convertir el dolor de los sujetos en impulso de emancipación, entraría a romper con una tradición conservadora 
del pasado, que siempre ha atado las posibilidades de surgimiento novedoso de las formas sociales del pueblo (cf. Mate, 20I I: I65-I82). Ella pondría en exposición el conflicto y el desafío de crear ámbitos de ampliación discursiva ante la dispersión de los acontecimientos y el reaccionarismo histórico que embotan y paralizan.

Si nuevos lazos han de ser tramados, esperamos que no se ordenen alrededor del uso de la racionalidad deliberativa fabricada con el refinado lenguaje compartimentador de las nuevas éticas. Dada la opacidad y ambigüedad de los mecanismos presentes en la gestión comunitaria y local de las demandas por justicia y derechos, es fundamental intentar percibir la resonancia de eso en un modelo de democracia deliberativa orientado hacia la negociación y los acuerdos. Sobre todo, con el sesgo parcializado implícito en el caso de muchas de nuestras conservadoras sociedades latinoamericanas, donde las diferencias se resuelven en el plan de afiliación social y moral. Corroborado, además, por la falta de valores políticos rivales organizados alrededor de una idea de la justicia acorde a un trasegar histórico real e inmanente. Así que nos alineamos a la inquietud de Chantal Mouffe sobre las oportunidades de disponer de un lenguaje ético para la democracia que pudiera dar lugar a un encaje apto a asumir la gestión común de los influjos constantes, y muchas veces enfrentados, de reciprocidad y de hostilidad de la esfera pública (Mouffe, 20I 2).

Uno de los grandes equívocos de ciertas propuestas de justicia consensual es confundir pluralidad con no homogeneidad y confrontación adversarial con exclusión de posiciones distintas. $\mathrm{Al}$ inverso, se pueden y se deben construir los eventuales consensos desde la inclusión de todas las diferencias en un plan de disputa política y de hegemonías muchas veces contrarias e irreconciliables, donde hay que reconocer al adversario sin excluirlo y promover una pluralidad atenta a sus límites de deliberación (Mouffe, 20I 2); conducida por el disenso como camino constante de cuestionamiento del consenso y de garantía de la no-exclusión, preocupación sostenida por el mejicano Luis Villoro desde el razonamiento de una ética concreta que atiende políticamente a la interpelación originada en una experiencia sentida de exclusión (Villoro, 2007: I 5-4I).

Es interesante mencionar, para la discusión de las fórmulas dispuestas en la realidad de los saberes homologados, el intento ejemplificado por la llamada mediación restaurativa. Esa herramienta, propugnada para la tramitación de conflictos entre víctima y victimario en los espacios instituidos de la justicia transicional, para el caso colombiano, o en muchos modelos de justicia con- 
sensual, estaría, desde nuestro punto de vista, sirviendo como una técnica de terapéutica social, en que a través de la empatía se busca ponerse en el lugar del otro y luego solucionar tópicamente una situación visible e inmediata. Como si fuera posible la operación de poder sentir y comprender la irreductible diferencia puesta por la alteridad del otro, cualquiera que sea su condición, puesta enfrente. Ya que cuando presumimos conocer el sentimiento o la sensación ajenos lo que se hace es justamente destituir al otro, eliminándolo en su capacidad de elaborar una narración original sobre el conflicto; impidiendo también la comprensión más amplia e imparcial de la situación. Pero inclinación diversa es la que propicia la compasión, comprometida éticamente con la solidaridad, que sólo puede darse en el reconocimiento sin más del otro, poniéndose a su lado, ofreciéndole escucha y cuidado. Es así como nos convoca a ese cometido Deleuze al comentar la inquietante novela de Melville, Bartleby el escribiente, poniéndose a escudriñar sobre las motivaciones que llevan a que los miembros de una comunidad puedan fabricar una moral vital y fraterna (cf. Deleuze, 20II: 88-89): "¿Qué pide Barteleby si no es un poco de confianza, mientras que el abogado le ofrece únicamente caridad y filantropía, todas las máscaras de la función paterna?» (Deleuze, 20I I: 89).

Tratándose de la producción de una moralidad encarnada en nuestros gestos y acciones, la que saltase de una respuesta institucional de justicia a una relación mucho más simbiótica con las experiencias de injusticia, podríamos, a modo de una digresión tentativa, distinguir dos cualidades de implicación ética, que van a permitir, a su vez, dos grandes abordajes de la justicia. Una primera, derivada de la obediencia a un comportamiento y dirigida a la concreción de reglas de tipo universal, las que estarían consignadas en el ejercicio de las libertades, tanto negativa como reflexiva; y una otra, asumida desde la raíz de un sentimiento emanado de las situaciones y de los contextos de falta de libertad y de constatación del daño presentes en la esfera de la objetividad (cf. Honneth, 20I4) ${ }^{4}$ En donde encontramos, para

4. La distinción que enunciamos busca recorrer, sin explayarse, por un costado, el conjunto de las configuraciones filosóficas que hicieron posible el surgimiento en la modernidad de la idea de la defensa de la anulación de los impedimentos a la libertad de acción de los sujetos, erigida a partir de Hobbes; y luego, la construcción de la libertad afirmada en la autonomía y la autorrealización, inaugurada por Rousseau y desarrollada por Kant, Mill y Rawls, para citar algunos (cf. Honneth, 2014: 3663). En el otro margen estarían representadas las disposiciones morales que Honneth 
este segundo caso, expresiones más fuertemente normativas, como la que propone Axel Honneth, siguiendo a Hegel, bajo la clausura de una eticidad comprometida con ideales y valores legitimados por la sociedad y validados por las instituciones (cf. Honneth, 20I4: I3-25); y la que destaca Simone Weil cuando apela a una especie de reconstitución permanente de los momentos de verdad, en que irrumpe «esa parte del corazón que grita contra el mal» (Weil, 2000: 19), movimiento de invasión que se da menos por el uso de las libertades democráticas que por la atención y el silencio puesto sobre las cosas (cf. Weil, 2000: I9).

En suma, nos queda como tarea, sobre esas vertientes de un pensamiento conmovido por las injusticias y empeñado en su lucha política, captar las señas propicias desde donde instaurar la elaboración del conflicto y la concreción de un ethos no falacioso de comunidad. Mirando a conquistar el reconocimiento fructuoso de la perspectiva de los pueblos, en especial, de las culturas subalternas, comprendidas en su vitalidad y fuerza intrínseca y en su mundo de la experiencia práctica, como recuerda a contracorriente Ginzburg (cf. Ginzburg, 2014: 32-36), mundos en que la vivencia de negación o afirmación de la justicia penden, en ritmo creciente, del inescrupuloso hilo de intereses ajenos a la soberanía de los sujetos.

\section{Justicia comunitaria: la bitácora perdida}

El paradigma ético-político de la justicia comunitaria viene hablar de expresiones de juridicidad alternas encaminadas a la sustanciación de los vínculos sociales y la reordenación de la posición del sujeto desde la cual irrumpe ante los sistemas de cosificación de la existencia. Entre las posibilidades de asumir una postura emancipada y crítica para los sujetos está la invitación antisistémica de justicias erigidas sobre la complejidad asimétrica de los individuos y la toma intercultural de la palabra que invoca, al permear las relaciones entre los grupos y al interior de ellos.

utiliza para ordenar una eticidad basada en la concepción hegeliana de libertad social, preocupada por la creación de las condiciones reales de disfrute de la libertad, que sólo puede ser capturada en la plena relación de reconocimiento mutuo, o de realización de sí mismo en el ser del otro (cf. Honneth, 20I4, 64-90). Es la correspondencia de esta corriente filosófica con una moralidad comprometida y contextual la que pretendemos subrayar más tarde en la caracterización de nuestra propuesta de justicia comunitaria. 
Hemos perseguido, con esa fe e intencionalidad, el camino de las dichas prácticas contrahegemónicas del derecho, como es la llamada justicia comunitaria. Y nos hemos parado ante el esfuerzo filosófico y reflexivo, abandonando, en gran parte, la creencia procedimental en los derroteros emancipatorios de la racionalidad comunitaria. ${ }^{5}$ Pese a nuestra convergencia en la finalidad política de creación de una institucionalidad popular y participativa, defendida con brillantez y correcta visión por Edgar Ardila, el principal teórico de esas prácticas alternativas, acudimos al contraargumento de que la exigencia de producción de norma social y de existencia de comunidad restringe las posibilidades concretas y discursivas de las variadas especies de vinculación colectiva constructoras de horizontes normativos y de otras tantas relaciones comunitarias de intercomprensión subjetiva. ${ }^{6}$ Animados por ese convencimiento, hemos intentado reencontrar las sendas por donde la justicia se pueda hacer al lado de la acción crítica canalizadora de los disensos.

La idea de una justicia comunitaria toma así la dimensión de un emprendimiento político y epistemológico erguido sobre la prioridad de la vivencia de la injusticia, proyectado sobre dos grandes plataformas: el lenguaje del conflicto y la interpelación moral de los sujetos. Esos dos pilares ya venían desde hace mucho insinuándose en nuestras investigaciones. Desde cuando empezamos a posicionar la justicia comunitaria como una ruta teórico-metodológica capaz de incidir en los conceptos y las prácticas ya adquiridos y en cauce de transformación de la justicia. Por lo que se fue precipitando, para su concreción, la doble vía de la exteriorización político-cultural mediatizada por la resolución pedagógica de los conflictos. Engendrando a través de la experimentación po-

5. Es cierto que en esa compenetración terminamos reencontrándonos y refutando la teoría de la justicia comunitaria del profesor colombiano Edgar Ardila, cuya caracterización se asienta sobre la asociación funcional de las nociones de norma social y comunidad, ejes estructuradores de la definición de esa modalidad de administración de justicia (Cf. Ardila, 2006).

6. Los elementos más enraizados que presentaremos de la justicia comunitaria han sido descubiertos hace algún tiempo en los análisis etnográficos, de incidencia éticopolítica en la formulación de estrategias de despliegue comunitario, del antropólogo Jorge Gasché. Para los propósitos de ese autor, la actividad social sería el centro irradiador de la práctica educativa, pues es sobre ésta, con sus discursos, gestos y semánticas, que se procura mover las estructuras políticas interiorizadas por los dos actores, el educador y el alumno. 
lítica el camino de desarrollo de las estructuras de autonomía comunitaria; y, simultáneamente, incorporando y renovando esquemas y patrones del mundo social en el ejercicio de escritura del entramado cultural. De ahí se desprendieron las categorías mencionadas.

Interponemos para la asunción del ámbito del discurso, el lenguaje del conflicto. Entendido como recurso discursivo social y existencial que forma vínculo entre los sujetos y converge hacia la formación de horizontes normativos. Mientras que la idea de interpelación moral de los sujetos, referida al elemento pragmático, conduce a una concepción bastante crucial a la filosofía práctica, cual sea la de alteridad u otredad. Cuando nos instalamos en el lenguaje del conflicto estamos transitando por la carne, los nervios y el corazón del conflicto, trasegamos por su corporeidad, traducida en sentimientos, pasiones y razones expresos en narrativas, interpretaciones y argumentos. Él permea y constituye el propio accionar de los sujetos. Dentro de la antropología cultural, podríamos decir que remite al enfoque diatópico, el cual recoge y atraviesa los distintos lugares comunes de comprensión asentados en la vida humana (Vachon y Coll, I996).

En ese sentido, es contundente la afirmación de George Bataille traída por Roberto Esposito al afirmar que «la comunicación no tiene lugar más que entre dos seres puestos en juego — desgarrados, suspendidos, inclinados uno y otro sobre su nada» (Esposito, 2009: I 5). Y si queremos apoyar ese pensamiento posestructuralista en el terreno de lo político, podríamos acompañar a la profesora belga Chantal Mouffe al convocar a la confrontación agonística, dentro de su particular lectura de Carl Schmitt respecto de la creación de un espacio democrático de disputa de hegemonías y enfrentamiento de posiciones adversarias, capaz de transformar los antagonismos excluyentes y destructivos en confrontaciones enriquecedoras del debate público y político (Cf. Mouffe, 2OI2: I7-72). En esa dirección y para lo que queremos promover alrededor de los medios inscritos en las prácticas de justicia comunitaria, podríamos afirmar que el conflicto vendría a ser el propio paradigma discursivo de ordenación de los debates, sostén y agente de las mediaciones.

A su vez, la interpelación moral de los sujetos recubre el espectro de las relaciones de intercomprensión y que correspondería al otro hincapié antropológico, el de la visión dialógica, la que atraviesa la razón con la cual nos movemos y juzgamos para llegar a tocar el nudo íntimo y mítico de las culturas (Vachon y Coll, 1996). Propiciando el despliegue de identidades colectivas cambiantes que, por cierto, como nos ilustra con claridad Mouffe, hacen apelo a la contaminación de las formas y de los sentidos, en respuesta a la supuesta 
voluntad establecida de negociación o mediación (cf. Mouffe, 20I2: I7-72). La contaminación referida no es sino aquella apertura a la invasión persuasiva y contagiosa de otros seres, sin la cual la individualidad correría el riesgo de naufragar en sus fijaciones hedonísticas.

Dando curso al planteamiento expuesto, cabe además ponderar al respecto del significado de comunidad en la articulación del acogimiento de la alteridad con las vías aptas para la praxis colectiva. Las formulaciones establecidas del término comunidad en la teoría política ciertamente no nos garantizan de entrada la aprehensión más robusta y más proclive a la promoción de una espacialidad exenta de enajenación y apropiada por los individuos que la componen. Explica Esposito que tradicionalmente las ideas de comunidad - el organicismo alemán, el neocomunitarismo americano y la ética de la comunicación de Habermas y Apel- nos indican que están constituidas contra el trasfondo de la categoría de sujeto, siendo este el portador y portavoz de los caracteres propios de esta o aquella unidad de identificación (2009: I4-I5). Lo que conlleva a que el concepto de comunidad recaiga fuertemente sobre un matiz semántico con un alto componente de propiedad identitaria particularizada y definitiva. Si continuásemos desplegando el término en este orden, sin someterlo a la revisión crítica necesaria, que remite a su apertura y distensión, como lo hacen Jean-Luc Nancy y Esposito, se obstaculizaría justamente el cierre que propicia la exposición del individuo y el puente tendido hacia los otros (cf. Esposito, 2009: I 5-I 8), 7 ante el cual se arraiga la afectación recíproca, que representamos por la interpelación moral de los sujetos, actitud objetiva y creadora de los deseos de unión y vida en común que extrapola la circunscripción de las afinidades y caracterizaciones. Proceso claramente contrario a los influjos de totalización igualitaria, de los cuales tampoco se percatan muchos de los grupos adscritos al aseguramiento de una identidad diferenciada. ${ }^{8}$

7. En palabras de Nancy, «la comunidad no es un ser común, sino el modo de ser en común de una existencia sin esencia o coincidente con la propia esencia» (Esposito, 2009: I6). Ya Esposito se apoya en la retomada del concepto originario de communitas, "aquello que liga a sus miembros en una voluntad de donación hacia el otro» (Esposito, 2009: I7).

8. Para una crítica aún bastante actual de esos mecanismos de fetichización de la identidad, aunque sin todos los alcances implícitos en el trascurso actual, vale la pena conferir las colocaciones de Erich Fromm, como ésta: «todos obedecen las mismas órdenes, y no obstante, todos están convencidos de que siguen sus propios deseos. Así 
Será quizás esa misma intención valorativa profunda de encuentro compasivo entre los sujetos la que se ve tangible en la formulación de las relaciones de reconocimiento mutuo elaborada por Hegel, poniendo de antemano el tipo de inversión ética hecha previamente sobre los aparatos institucionales en los cuales deben ceñirse los fines de todos los individuos (cf. Honneth, 20I4: 64-90). De aquí podemos obtener también la fundamentación necesaria para guiar el proceso valórico-normativo ${ }^{9}$ de la justicia comunitaria que se quiere detallar. Desvelando ese mismo nivel pragmático en donde se desliza por una casi deriva ética la interpelación moral de los sujetos, ya que el riesgo de una marcha sin rumbo es siempre latente, nos deparamos con los mundos de la vida de manifestación ontológica, lugar en que se dispersan y superponen un sinnúmero de contextos de sentidos fuera de orden y de la trama discursiva. Este lugar de soporte ético formado en el palimpsesto de sentidos implícitos y connotativos es, por esa antinómica función de ingravidez, el reservorio de significados no desarrollados en la arena discursiva. Es en esa forja de sentidos que descubrimos, tarde o temprano, el calado y el calibre de las investiduras con las que tallamos nuestros horizontes de verdad y de escucha; comprendiendo, con José Luis Pardo, que «un contexto (empírico, explícito, denotativo: el dormitorio, la cocina o el salón) no es más que el mínimo de condiciones restrictivas requerido para captar algo que está por completo fuera de contexto, que no es empírico, ni explícito, ni denotativo, ni dormitorio, ni cocina, ni salón ni despacho: otra habitación, una habitación cualquiera y, sin embargo, una diferencia, una singularidad (¡no una identidad!): una letra (muerta, no interpretada)» (Pardo, 20II: I82).

Podemos entonces imaginar la vectorización que se establecería a partir de ese núcleo de valores e ideales prediscursivos hacia la esfera de lo político, el mundo simbólico de las evidencias empíricas y de ordenación de regímenes discursivos instaurados por los distintos flujos de lenguaje del conflicto, desde el cual igualmente se dislocan sentidos moldeadores y modeladores de la acción. De ese corredor de sentidos se extraerían finalmente, como resultado tangente, nuevos contextos y nuevos significados, instituidores de lo que denominaría-

como la moderna producción en masa requiere la estandarización de los productos, así el proceso social requiere la estandarización del hombre, y esa estandarización es llamada 'igualdad'» (Fromm, 1974: 25).

9. Expresión extraída directamente de los diálogos llevados a cabo por vía electrónica con Ricardo Salas, quien la utilizó en su percepción epistémica del tema en cuestión. 
mos como mundo de la diferencia y de la singularidad. Descomponiendo la ilusión de la racionalidad deliberativa moderna de ver reconciliadas y fundidas las dimensiones ética y política, sabiendo «que el campo de lo político no puede reducirse a un cálculo moral racional y que exige siempre la toma de decisiones» (Mouffe, 20I2: I 5I) y que tenemos que soportar en cuanto designio humano inacabado la exigencia de responder a la inconmensurabilidad de los destinos éticos posibles (cf. Mouffe, 2OI 2: I 4 I-I 5I). ${ }^{10}$

Nada más restando que pretender un pasaje ético y performativo (cf. Derrida, 20IO: 5 $\mathrm{I}-58)$ para la realización de la justicia, advenida en tanto acto de lenguaje fundante, reencontrado con su discursividad creadora y los resortes comunitarios más hondos e internos de la vida de los seres. Por eso, no olvidemos que mas allá de pregonar un horizonte de espera, la justicia, en su urgencia impostergable, recuerda Derrida, «no tiene horizonte de expectativa (reguladora o mesiánica). Pero, por eso mismo, ella tal vez tenga un futuro, justamente, un por-venir» (2010: 54; la traducción es nuestra).

Dentro de la propuesta de una justicia tejida por una creación semántica intrínseca a los conflictos, podemos finalmente ver que el salto requerido se daría en la inversión de una serie de supuestos organizadores de las prácticas, trasladándose continuamente del énfasis procedimental al contextual, de la racionalidad moral a la política, de la teleología funcional a la sustancial, de la producción de normas al reconocimiento pleno y verdadero de las diferencias, del establecimiento de factores estructurales al planteamiento de patrones y esquemas paradigmáticos y, por fin, de un abordaje estático de conformación normativa y comunitaria a uno dinámico.

Es, en últimas, la afirmación de un propósito de fundamentar el campo de toma de decisiones de la justicia sobre una determinación ética (Mouffe, 20I2). Y no como una mera prolongación de la materialidad política concertada racionalmente (Young, 2000). Lo político debe mantener su lugar yuxtapuesto pero no superpuesto al dominio ético, para evitar que nos detengamos

ıо. Complementando la raigambre filosófica, insisto en la fibra moral que debemos contener, nos servimos de la bella descripción de Alain Badiou: "Con alegría hay que aceptar que el destino de toda situación sea la infinita multiplicidad de los conjuntos, que ninguna profundidad pueda establecerse jamás en tal multiplicidad, que la homogeneidad de lo múltiple venza ontológicamente el juego de las intensidades. Y que, por consiguiente, abandonando el anclaje en toda finitud, habitemos en el infinito como en nuestra morada absolutamente anodina» (2002: 2I). 
en la irresistible necesidad de sumirnos al consenso de intereses, olvidándonos del sujeto moral. Empero, de modo contrario, estaríamos inevitablemente atentos a la exclusión, a la falta de valorización y al no reconocimiento que marcan la injusticia y las debidas razones para disentir, para escapar del poder e interrogar al otro que excluye. Y luego fabricar nuevos consensos instruidos sobre bienes comunes elegidos (cf. Villoro, 2007: I 5-4I).

Por cierto que un proceso de descolonización del sometimiento de las redes jerárquicas del derecho estatal y sus prolongaciones paraestatales, como las que se diagnostican en la capilaridad de los dispositivos de pacificación y confinamiento, tendría que revisar cuidadosamente la opción de diálogo con las estructuras del derecho puesto. Quizás, más que entablar un comercio lingüístico con las ofertas regulatorias del matematismo estatal, lo que llevaría a seguir sosteniendo la clausura de lo jurídico en la centralidad del Estado, las energías críticas lucirían mejor por medio del ejercicio de restitución ideológica de derechos subalternos y alternos, en aras de invertir los parámetros de la reflexión político-filosófica. Aspirando así, a que el estatus de control racional del derecho estatal gobernante sea destituido, trasmutando la escena de la vida política a una arena de diálogo agonístico, luego, proclive a la autonomización de los pueblos, considerados en su mundo simbólico y territorial.

No fuera sólo por su importancia seminal en el desarrollo de las respuestas que podemos como sociedad brindar a nuestras ausencias y deficiencias constitutivas en la elaboración de un derecho acorde a nuestra singularidad histórica, nos vemos ante la necesidad de rediseñar las mismas bases políticas y filosóficas de lo que entendemos por justicia, comunidad y derecho. Lo que nos arrastra finalmente a pensar la idea de justicia por otras aristas, conociendo su reiterada ausencia y negatividad y persiguiendo su virtud de acogimiento y constante indagación.

\section{Justicia: locus performativo de un lenguaje para el disenso}

Desde las juridicidades expresadas por las diversas formas de emanación de la justicia comunitaria y su respectiva red de principios, erigida sobre la realización de las necesidades humanas, el reconocimiento de las identificaciones grupales y las propiedades singulares de los procesos de ordenación sociales, conviene establecer una base de entendimiento de este manifiesto de posicionamiento político-filosófico. Desde ahí, apostamos en una acometida epistemológica, que cubra y expanda los campos de la acción política y moral vigentes, 
con el fin real y deseado de incidir en conceptos y prácticas, operacionalizando la comprensión de determinados conceptos y apoyando la efectividad de ciertas prácticas, convergiendo así a la postulación de valores y referentes de concretización de las distintas expresiones de justicia comunitaria.

Siendo la justicia comunitaria una idea que desdobla la visión moderna liberal de regulación de las conductas, miremos como se desplegaría ese nuevo paradigma de configuración jurídica. Partimos del presupuesto irrevocable de que un cambio cualitativo en el carácter del modelo de producción material de la vida, incluidas ahí las mudanzas significativas de los sistemas educativos y sociales, requiere romperse con determinadas lógicas dominantes de perpetuación capitalista excluyente (cf. Meszaros, 2008: 25-35). Esa ruptura tendría que estar irresolutamente acompañada de un movimiento cultural y propositivo de respuestas potenciales, dispuestas a resolver algunas contradicciones de fondo que impiden una alianza sensible entre las fuerzas emancipatorias y creadoras de la sociedad. Sostenemos que con el fin de combatir los problemas fundamentales de explotación económica e inequidad histórica sufridos por un gran grupo de la población de nuestras regiones siempre tan amenazadas (que no están solas en éste y en muchos otros aspectos), debe darse apertura a las libertades de espíritu propulsoras, exentas de concesiones reformadoras. Serán ellas las que superarán el nivel visible de las estructuras, donde las determinaciones cruciales no pueden ser alteradas. Lo estructural, al constituir el esqueleto vital de una ordenación dinámica, resiste al sometimiento y la recomposición. La alternativa de acción radical para los sujetos de una vía política reconstructora encuentra, sin duda, asidero en relaciones pedagógicas de confrontación y diálogo, las cuales pueden transponer los lugares sociales establecidos y abrir paso a la manifestación de los elementos vivos del lenguaje que son, en últimas, los que pueden armar un nuevo horizonte ético, político y epistemológico.

Creemos que ninguna transformación sustancial en nuestra escala de valores y conjunto de ideas ocurrirá sin el avance de soluciones responsables. En el campo de nuestra reflexión — la justicia comunitaria-, la elaboración de parámetros propios de concreción de la justicia a través de dispositivos sociolinguísticos de interpelación y articulación de los componentes del conflicto, ahí incluidos los individuos, los temas y las situaciones de vida, permite desarrollar experiencias significativas y formadoras. Por lo que consideramos que la proyección ético-política engendrada por medio de la justicia comunitaria impacta profundamente la interiorización de los derechos, que es otro modo 
de hablar de su indispensable eficacia simbólica. Si asumimos, claro, un proceso de problematización crítica y reflexiva de dicho lenguaje de los derechos, comprendido como el rol de combinaciones sintácticas empleadas en los intercambios textuales de los sujetos.

Eso afirma una respuesta en la dirección exactamente contraria a las imposiciones de la violencia, donde se anulan las vías mediatizadas de aseguramiento de los límites mínimos de la convivencia y de las reglas convenidas. Sin embargo, la sola existencia de canales instituidos y autorizados de tramitación de los referentes valorativos y estructurales preponderantes es insuficiente para hacer el cuestionamiento de los métodos, contenidos y formas de las políticas de conformación de consensos (cf. Meszaros, 2008: 35-47). ${ }^{11}$ Hay que leerse la realidad constantemente con el fin de adelantar los embates esenciales y levantar el polvo ideológico de los argumentos sacralizados, donde las consignas del mercado ejercen su capitulación en todos los frentes. Por eso la exigencia de la interlocución cualificada, materializada en los encuentros de intereses ${ }^{12}$ y en las disputas de fuerzas alrededor de la hegemonía de ciertas prácticas y saberes emergentes. A partir de ahí es posible expandir la zona de percepción del conflicto y del uso potencial de la palabra, escalando los escollos del entramado de los vínculos; subvirtiendo incluso cierta dialéctica comunicativa siempre dispuesta a zanjar controversias. Más allá de la gestión procedimental de «casos de conflicto", lo que se conduciría con el enfrentamiento desvelado de los desacuerdos y las divergencias sería la puesta en marcha de una acción reveladora, mediada por la explicitación de evidencias rastreadas en el acervo discursivo de las personas insertas en el problema.

I I. Véase a ese respecto la claridad de los planteamientos de Mészáros, quien resalta con detenido énfasis la necesaria reformulación estratégica de la educación institucionalizada enlazada con el árbol de significados alimentadores de la vida social (2008).

I 2. Es curioso resaltar la disparidad de la idea de encuentro de intereses aquí utilizada ante la proposición sostenida por el Consejo Nacional de Justicia de Brasil en relación a las medidas de formateo del nuevo tipo de atención judicial promovida, al declarar en el título de su Resolución I25: "Dispone sobre la Política Judicial Nacional de tratamiento adecuado de los conflictos de intereses en el ámbito del Poder Judicial». Además, siguiendo la coherencia de su política de soporte y control de los mecanismos de procesamiento jurídico, describe en el art. I como su principal objetivo «ofrecer otros mecanismos de solución de controversia, en especial los llamados medios consensuales» (Conselho Nacional de Justiça, 20ı ; trad. nuestra). 
Al observar el panorama de estrechamiento de modos de contrapoder que alternen la visión alienante de los esquemas político-jurídicos de contención y aislamiento de los conflictos, somos instigados a pensar en términos de un proyecto histórico y social de desmanche del sometimiento a través de la reanimación de la conciencia, usualmente cotejada con los soportes de la razón y desencadenada de las vívidas peripecias de una voluntad autoescindida (cf. Bahnsen, 20I 5: 62-79). Lo cual se imaginaría, en síntesis, a partir de acciones permanentes de interacción entre el punto de representación político-ideológico, simbolizando el marco sistémico de manutención, y el punto ético-cultural, señalizando la coyuntura espacio-temporal factible de ser embestida por episodios de movilización. El tipo de instrumentos empleados, tal cual la vía de reconducción crítica de nuestros hábitos, comportamientos y procesos modelares, se convierte en la pieza primordial al descortinamento subjetivo, que se desea sea recogido en los conceptos y las prácticas concernientes al enfrentamiento de la conflictividad y sus correspondientes impases políticos.

Reanudando la propuesta de proyección ético-política desde la asunción de modelos empíricos existentes de justicia comunitaria al interior de los contextos de nuestros países, somos conllevados a admitir la exigencia clave de un proceso descolonizador de autorreconocimiento y aceptación. Recuperación de memorias, de relatos y narrativas ${ }^{13}$ aprehenden el bosquejo principal de ese trabajo consciente de reorientación paradigmática. Ni mera oposición como medio de negación, ni complementariedad como esquema de acoplamiento funcional, ni una dialéctica compresora pueden dar cuenta de la lectura de realidades tan groseramente amalgamadas; lo que se debería propiciar es del ámbito de un movimiento reconstructivo o de suplementariedad (cf. Figueiredo, I999: 24-39) ${ }^{14}$ que se da «en la justa medida en que ciertos velos se rompen

I3. En alusión a la obra de Jean-Marc Ferry, La ética reconstructiva (trad. Diana Muñoz González, Bogotá, Siglo del Hombre Editores, Universidad Nacional de Colombia, Embajada de Francia, 200I). A medio camino entre la procedimentalización argumentativa del derecho y el cometido de proponer una justicia substanciada, se ciñe su pensamiento a «retomar el origen mismo de la experiencia vivida por los interesados, y, al hacerlo, suscitar procedimientos discursivos que suponen la narración y la interpretación, registros todos que están situados lógicamente río arriba de una argumentación que se limita a justificar la regla o a articular la confrontación de las partes de un modo contradictorio» (7I).

I4. En alusión a la propuesta de Luís Claudio Figueiredo para una interpretación 
y podemos, por unos instantes, entrar en contacto con nuestros subterráneos» (Figueiredo, I999: 25; trad. nuestra). Las místicas culturales que han delineado nuestra identidad de pueblos colonizados dificultan sistemáticamente la aparición de arreglos sociales menos torcidos en su imagen y, al tiempo, más operantes en su integridad interna. En ese sentido, el ejercicio de una lógica de suplementariedad que expandiese los horizontes de regulación e intercambios societarios podría producir gradualmente salidas no estandarizadas de actualización democrática, pautadas en la superación de patrones de inculcación reactivos y opresores.

Una apuesta de ese talante pide la participación de todos los sectores de la sociedad, de modo que se realice el emprendimiento de una zambullida crítica y visceral. No sobra remarcar que para trillar ese camino la elección de opciones conmovidas y benevolentes resulta estéril, cuando no son con frecuencia la causa del alargamiento temporal de los males y de los conocidos escapes cíclicos. Es esa la razón sobre la que se otorga Wilde para exponer su absoluta disidencia a los regímenes de altruismo piadoso y recordarnos que «los peores señores eran los que se mostraban más bondadosos ante sus esclavos, pues así impedían que el horror del sistema fuera percibido por los que sufrían, y comprendido por los que lo contemplaban» (Wilde, I983: Io). Escabullir a los mandamientos contaminados de sensibilidad filantrópica, ante las ruinas humanas generadas por la voracidad rentista de algunos privilegiados, puede conducirnos por unos derroteros de recreación de la alteridad, pilar definitivo del trabajo de disolución de identificaciones que cercenan lazos sociales y recluyen los sujetos a comunidades de víctimas; cuando abarcaríamos más sólidamente el daño y el conflicto desde la lógica circundante (por la función de atrape en zonas de disparidad) de la subjetivación política alentada por Rancière (2006: $17-39) .{ }^{15}$

psicoanalítica del síntoma social brasilero que, al igual, nos parece sumamente adecuada para dimensionar las lagunas y zonas obscuras implícitas en la tarea de reposicionamiento de la identidad de las sociedades latinoamericanas. La lógica de la suplementariedad se ofrece como una alternativa viable de constitución de parámetros civilizatorios más coherentes con nuestras capacidades conscientes y afectivas de resolver nuestros dilemas identitarios congénitos (I999).

I 5 . Así responde Rancière a la descripción de su arquitectura política: «Por un lado, no quedamos encerrados en la alternativa del universalismo o del identitarismo. La alternativa está más bien entre subjetivación e identificación. No opone universalismo 
Como avance reconstructivo, podríamos caminar en dirección a la producción de relaciones horizontales y mediadas por los flujos, contradicciones y embates sociales. En términos de regulación normativa de la pléyade de situaciones del convivir diario, apostamos en la potencia expansiva de los conflictos, a partir de los cuales se instaura una especie de catarsis en diapasón de los eventos contemplados. Desde ahí surge el lenguaje propio de elaboración de los derechos, lugar que se encuentra al revés de cualquier formalización técnica o burocrática, y donde se logra comprender las lógicas y significados que sufragan el tono de cada experiencia.

En conclusión y avanzando en lo que anteriormente pronunciamos, cabría trazar un proyecto ético-político de materialización de justicias comunitarias, que reposara sobre la triple agencia pedagógica de los siguientes puntos: I) la afirmación de un lenguaje, anclado en la reflexión de la palabra y en la escucha con el fin de cifrar los horizontes normativos presentes; 2) la invocación colectiva de los acontecimientos de modo a articular las memorias y los signos del padecimiento hacia la revitalización de los vínculos de la comunidad; y 3) la legitimación cohesionadora de saberes, en tanto práctica de gestión del repertorio de nuevos sentidos fomentados por los dilemas y las discrepancias al interior de los grupos. Más allá de eso, es descifrar el contenido intrínseco de las prácticas que, por supuesto, siempre traspasan la altitud de nuestros módicos intentos de contornarlas.

No obstante, cabría lanzar un marco, sino definitivo, al menos tentativo, a partir de lo que hemos buscado pronunciar con los planteamientos anteriores. Haciendo hincapié en el nudo problemático del reconocimiento de la diferencia, recodo sustancial de la caracterización de los sujetos, en tanto suele exigir la inscripción de identidades numerarias y categorizantes, confiamos, a contrapelo, en una pragmática del lazo social. Fundada en el poder vinculador de la palabra, matriz de un lugar-entre-sujetos, de ese modo, salpicado en los despliegues inconclusos de la exacerbación del conflicto (lo político) y fuertemente anclado en la interculturalidad rebosante del cuerpo a cuerpo de los goces

y particularismo, sino dos ideas de la multiplicidad. El discurso universalista también puede revelarse tan 'tribal' como el discurso comunitario. [...] La verdadera oposición separa más bien lo tribal y lo idiomático. La política 'idiomática' construye un lugar de lo universal, un lugar de demostración de la igualdad. Separa el dilema sin esperanza que opone la gran comunidad y las pequeñas en provecho de una comunidad de los intervalos» $(24-25)$. 
propios de cada individuo (lo ético). La referida pragmática del lazo social, al desmantelar la utopía del consenso, como lugar tendiente a la normatización de las diferencias, reivindica una justicia antisimétrica, que desincorpora la falsa simetría de la equidad distributiva y, a la vez, introduce el principio del don y del afecto, incidiendo en la formulación posible de una justicia participativa y relacional, la aquí denominada justicia comunitaria. En ese nivel de desvelamiento de una reciprocidad aparente, fabricada entorno de un conjunto de trueques e intercambios materiales, el sujeto, por lo que ya no se encuentraría adscrito a una hermandad artificial, puede decir — previo a toda refrendación colectiva- «yo soy el otro». Con ese supuesto de partida se abrirían las sendas a otro régimen discursivo, capaz de acoger en extensión el dolor y el sufrimiento, y a otros procesos de reconstitución de los acontecimientos de (in)justicia.

\section{Referencias}

Ardila Amaya, Edgar (coord.) (2006). ¿A dónde va la justicia en equidad en Colombia? Medellín: Corporación Región.

Badiou, Alain (2002). Breve tratado de ontología transitoria. Trad. Tomás Fernández Aúz y Beatriz Eguibar. Barcelona: Gedisa.

Bahnsen, Julius (2015). Lo trágico como ley del mundo y el humor como forma física de lo metafísico. Monografías situadas en los márgenes de la dialéctica real. Edición, traducción y notas Manuel Pérez Cornejo. Valencia: PUV.

Conselho Nacional de Justiça (20I0). Resolução 125, de 29 de Novembro de 2010. Ministério de Justiça. República Federativa do Brasil.

Deleuze, Gilles (20 I I). Barteleby o la fórmula. Trad. José Luis Pardo. En Melville, Herman. Preferiría no hacerlo. Barteleby el escribiente. Trad. José Manuel Benítez Ariza. Valencia: Pre-Textos.

Derrida, Jacques (2010). Força de lei: o fundamento místico da modernidade. Trad. Leyla Perrone-Moisés. 2. ${ }^{a}$ ed. São Paulo: Editora WMF Martins Fontes.

Esposito, Roberto (2009). Comunidad, inmunidad y biopolítica. Trad. Alicia García Ruiz. Madrid: Herder.

Figueiredo, Luís C. (I 999). Psicanálise e Brasil. Considerações acerca do sintoma social brasileiro. En Edson L. A. de Sousa (org.). Psicanálise e colonização: leituras do sintoma social no Brasil. Porto Alegre: Artes e Ofícios. 
Fromm, Erich (1974). El arte de amar. Trad. Noemí Rosenblatt. Buenos Aires: Paidós.

Gasché, Jorge. Niños, maestros, comuneros y escritos antropológicos como fuentes de contenidos indígenas escolares y la actividad como punto de partida de los procesos pedagógicos interculturales: un modelo sintáctico de cultura. Disponible en <http://www.pucp.edu.pe/ridei/pdfs/ninos maestros comuneros modelo sintáctico de cultura.pdf $>$.

Ginzburg, Carlo (20I4). Tentativas. El queso y los gusanos: Un modelo de historia crítica para el análisis de las culturas subalternas. Trad. Ventura Aguirre Durán y Carlos Antonio Aguirre Rojas. Bogotá: Ediciones desde Abajo. Honneth, Axel (2010). Reconocimiento y menosprecio. Sobre la fundamentación normativa de una teoría social. Buenos Aires/Barcelona: Katz/Centro de Cultura Contemporánea de Barcelona.

-. (2014). El derecho de la libertad. Esbozo de una eticidad democrática. Buenos Aires/Madrid: Katz/Clave Intelectual.

Martín-Barbero, Jesús (2010). De los medios a las mediaciones: Comunicación, cultura y hegemonía. Barcelona: Anthropos; México: Universidad Autónoma Metropolitana, Azcapotzalco.

Mate, Reyes (20I I). Tratado de la injusticia. Barcelona: Anthropos.

Meszaros, István (2008). A educação para além do capital. Trad. Isa Tavares. $2^{\text {a }}$ ed. São Paulo: Boitempo.

Mouffe, Chantal (2012). La paradoja democrática. El peligro del consenso en la política contemporánea. Trad. Tomás Fernández Aúz y Beatriz Eguibar. Barcelona: Gedisa.

Pardo, José Luis (20I I). Barteleby o de la humanidad. En Herman Melville, Preferiría no hacerlo. Barteleby el escribiente. Trad. José Manuel Benítez Ariza. Valencia: Pre-Textos.

Rancière, Jacques (2006). Política, policía, democracia. Trad. María Emilia Tijoux. Santiago: Lom.

Souza, Thaisa de (20I I). Justiça comunitária e emancipação na América Latina: a educação como pedagogia política. En Lauro Mattei (org.). América Latina no limiar do século XXI: temas em debate (pp. 227-245). Florianópolis: Insular.

Soler, Colette (20II). Incidencias políticas del psicoanálisis/ 1 y 2. 45 textos, ensayos y conferencias. Trad. Rithée Cevasco y Jorge Chapuis. Barcelona: S\&P Ediciones. 
Vachon, Robert Vachon y Augustí Nicolau Coll (I996). Etnicidad y derecho: Un enfoque diatópico y dialogal del estudio y la enseñanza del pluralismo jurídico. En José Emilio Rolando Ordoñez Cifuentes (coord.). Etnicidad y Derecho: Un diálogo postergado entre los científicos sociales (pp. 267290). V Jornadas Lascasianas, México: UNAM.

Valéry, Paul (1996). Política del espíritu. Trad. Angel J. Battistessa. Buenos Aires: Editorial Losada.

Villoro, Luis (2007). Los retos de la sociedad por venir. México: FCE.

Weil, Simone (2000). Escritos de Londres y últimas cartas. Trad. Maite Larrauri. Madrid: Trotta.

Wilde, Oscar (1983). A alma do homem sob o socialismo. Trad. Heitor Ferreira da Costa. Porto Alegre: L\&PM Editores.

Young, Iris Marion (2000). La justicia y la política de la diferencia. Trad. Silvina Álvarez. Madrid: Ediciones Cátedra, Universitat de València, Instituto de la Mujer.

\section{Sobre la autora}

Thaisa DE Souza es abogada y magíster en Filosofía, Sociología y Teoría del Derecho por la Universidad Federal de Santa Catarina (Florianópolis, Brasil). Ha sido docente de «Teorías Contemporáneas de la Justicia» y «Sociología Jurídica» de la Universidad del Rosario (Bogotá, Colombia) y fue directora de la línea de investigación «Justicia, Comunidad y Derechos Humanos» de la Maestría en Defensa de los Derechos Humanos de la Universidad Santo Tomás (Bogotá, Colombia). Actualmente es profesora en la Universidad Libre (Cali) y en la Universidad de los Andes (Bogotá), ambas con sede en Colombia, donde dicta la asignatura «Justicia y Comunidad». Investiga y estudia desde hace I 5 años el tema de la justicia comunitaria y sus proyecciones políticas y filosóficas en el contexto latinoamericano. Contacto:<thaisasouza@hotmail.com>. 